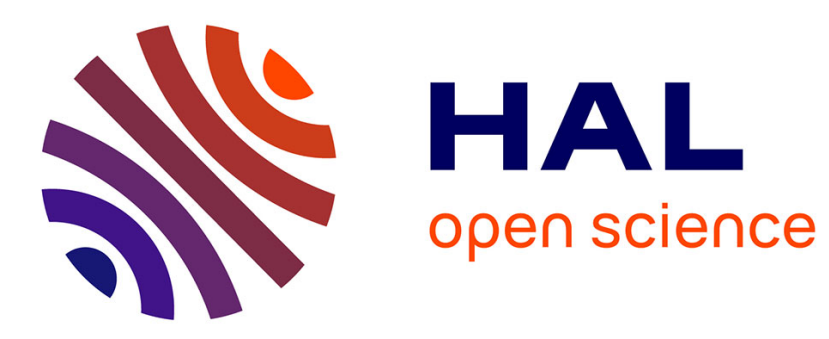

\title{
Why Do People Pay Taxes? Prospect Theory Versus Expected Utility Theory
}

\author{
Sanjit Dhami, Ali Al-Nowaihi
}

\section{To cite this version:}

Sanjit Dhami, Ali Al-Nowaihi. Why Do People Pay Taxes? Prospect Theory Versus Expected Utility Theory. Journal of Economic Behavior and Organization, 2007, 64 (1), pp.171. 10.1016/j.jebo.2006.08.006 . hal-00531866

\section{HAL Id: hal-00531866 https://hal.science/hal-00531866}

Submitted on 4 Nov 2010

HAL is a multi-disciplinary open access archive for the deposit and dissemination of scientific research documents, whether they are published or not. The documents may come from teaching and research institutions in France or abroad, or from public or private research centers.
L'archive ouverte pluridisciplinaire HAL, est destinée au dépôt et à la diffusion de documents scientifiques de niveau recherche, publiés ou non, émanant des établissements d'enseignement et de recherche français ou étrangers, des laboratoires publics ou privés. 


\section{Accepted Manuscript}

Title: Why Do People Pay Taxes? Prospect Theory Versus

Expected Utility Theory

Authors: Sanjit Dhami, Ali al-Nowaihi

PII: $\quad$ S0167-2681(07)00076-5

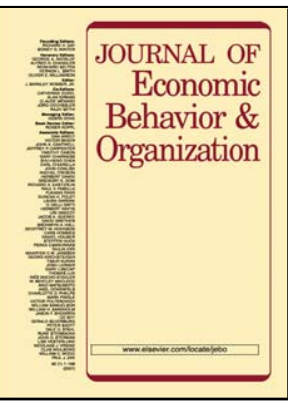

DOI: doi:10.1016/j.jebo.2006.08.006

Reference: $\quad$ JEBO 2096

To appear in: Journal of Economic Behavior \& Organization

Received date: 21-9-2004

Accepted date: $\quad 22-8-2006$

Please cite this article as: Dhami, S., al-Nowaihi, A., Why Do People Pay Taxes? Prospect Theory Versus Expected Utility Theory, Journal of Economic Behavior and Organization (2007), doi:10.1016/j.jebo.2006.08.006

This is a PDF file of an unedited manuscript that has been accepted for publication. As a service to our customers we are providing this early version of the manuscript. The manuscript will undergo copyediting, typesetting, and review of the resulting proof before it is published in its final form. Please note that during the production process errors may be discovered which could affect the content, and all legal disclaimers that apply to the journal pertain. 


\title{
Why Do People Pay Taxes? \\ Prospect Theory Versus Expected Utility Theory*
}

\section{Sanjit Dhami ${ }^{\dagger} \quad$ Ali al-Nowaihi ${ }^{\ddagger}$}

12 March 2007

\begin{abstract}
A bstract
Using actual probabilities of audit and penalty rates, the return on evasion is 91-98 percent. So why don't most of us evade? Existing analysis, based on expected utility theory (EUT) is unable to explain this. Furthermore, and contrary to intuition and the bulk of evidence, EUT predicts that evasion should be decreasing in the tax rate (Yitzhaki puzzle). We apply Kahneman and Tversky's (1992) cumulative prospect theory to tax evasion. We show that prospect theory provides a much more satisfactory account of tax evasion including an explanation of the Yitzhaki puzzle. This also provides independent confirmation of prospect theory.
\end{abstract}

Keywords: Reference Dependence, Loss Aversion, Decision Weights, Prospect Theory, Expected Utility Theory, Tax Evasion, Optimal taxation.

JEL Classification: D81 (Criteria for Decision Making Under Risk and Uncertainty), H26 (Tax Evasion), K42 (Illegal Behavior and the Enforcement of Law).

\footnotetext{
${ }^{*}$ We are very grateful for helpful comments at presentations of the paper at the Universities of Cambridge, Keel, Leicester, Nottingham and Warwick. In particular we would like to thank Toke Aidt, Joel Slemrod, Gianni De Fraja, Roger Hartley, J. Barkley Rosser, Jr., and two anonymous referees. The usual disclaimers apply.

${ }^{\dagger}$ Department of Economics, University of Leicester, University Road, Leicester. LE1 7RH, UK. Phone: +44-116-2522086. Fax: +44-116-2522908. E-mail: Sanj i t. Dha mi @l e. ac. uk.

${ }^{\ddagger}$ Department of Economics, University of Leicester, University Road, Leicester. LE1 7RH, UK. Phone: +44-116-2522898. Fax: +44-116-2522908. E-mail: a a10@ e. ac. uk.
} 


\section{Introduction}

Why do people pay taxes? Theoretical work, largely based on expected utility theory (EUT), has struggled to cope with the stylized facts. The tax evasion puzzle goes something like this. The (average) audit probability, $p$, is extremely low, with realistic magnitudes ranging from $p=0.01$ to $p=0.03$, while the penalty rate, $\lambda$, that is paid in addition to the payment of the evaded tax liabilities, ranges from 0.5 to 2.0; see, for example, Alm et al. (1992), Andreoni et al. (1998) and Bernasconi (1998). The seminal applications of EUT to the tax evasion problem, by Allingham and Sandmo (1972) and Yitzhaki (1974), show that the taxpayer will choose to evade taxes if the expected return per pound on evading the tax, $1-p-p \lambda$, is positive. Using observed values of $p$ and $\lambda$, the expected return on tax evasion is between 91 and 98.5 percent. The EUT account of tax evasion contradicts the empirical evidence in several ways. We focus on the following four.

1. With a positive expected return to tax evasion, EUT predicts that all taxpayers should hide some income. Taking account of unintentional mis-reporting of income, the evidence is that about 30 percent of taxpayers evade taxes; for instance, see Andreoni et al. (1998) and Slemrod and Yitzhaki (2002).

2. To square the predicted extent of tax evasion under EUT with the evidence, tax payers should be risk averse to an absurd degree; see, for example, Skinner and Slemrod (1985) and Alm et al. (1992) ${ }^{1}$.

3. Yitzhaki showed that using EUT under the reasonable assumption of decreasing absolute risk aversion, an increase in the tax rate leads to a decrease in tax evasion. In a large majority of the cases, experimental, econometric and survey evidence rejects this result. See, for example, Friedland et al. (1978), Clotfelter (1983), Baldry (1987), Andreoni et al. (1998) and Pudney et al. (2000). A notable exception, however, is Feinstein (1991).

4. Obligatory advance tax payments should not influence the taxpayer's evasion decision under EUT. This is because the carriers of utility under EUT are final wealth levels that are unaffected by the obligatory advance payments. However, empirical and experimental evidence show that obligatory advance tax payments reduce tax evasion; see, for example, Yaniv (1999).

Can the EUT framework be modified in some manner to take account of the tax evasion puzzles (1) - (4)? One possibility is that the stigma associated with being caught evading

\footnotetext{
${ }^{1}$ In one example, Skinner and Slemrod report a coefficient of relative risk aversion (CRRA) of 70 for EUT while realistic magnitudes of CRRA lie between 1 and 5 .
} 
taxes might make taxpayers reluctant to evade, despite the existence of a favorable gamble; see, for example, Benjamini and Maital (1985), Gordon (1989) and al-Nowaihi and Pyle (2000). Whether stigma can overturn tax puzzles (1) and (2) above is an empirical question. We find, in our calibration exercises, the answer to be in the negative. Furthermore, even the introduction of stigma does not address the tax puzzles (3) and (4) above.

The Allingham-Sandmo-Yitzhaki model has been extended in a number of directions to include endogenous income, dynamic effects, social norms, tax avoidance and uncertainty in the outcome of audits, among others; see, for example, Andreoni et al. However, as long as EUT is retained, the above paradoxes remain. Therefore, much recent work has investigated several non-EUT frameworks.

Bernasconi imposes a technical restriction on preferences called "orders of risk aversion" based on earlier work by Segal and Spivak $(1990)^{2}$. It turns out that for realistic $(p, \lambda)$ pairs, if risk aversion is of order 2 then tax evasion will take place, but if it is of order 1 it might not. However, not all technical restrictions on preferences are founded on independent empirical evidence, and, hence, it is not easy to evaluate their plausibility for specific contexts and for actual behavior; see for example, Starmer (2000).

Rank dependent expected utility theory (RDEU) can be viewed as EUT applied with a transformed cumulative probability distribution. This is of tremendous utility, since the whole machinery of risk analysis in EUT can be transferred to RDEU. This is Quiggin's correspondence principle (Quiggin 1993). In particular, a decision maker under RDEU will never chooses a first order stochastically dominated prospect.

Although RDEU can solve some problems of EUT (e.g., the Allais paradox), it cannot solve others (see, for example, problems 11 and 12 in Kahneman and Tversky 1979). Moreover, Eide (2001) showed that the paradoxical comparative static results of the AllinghamSandmo-Yitzhaki model carry over to RDEU. We therefore turn to a more radical departure from EUT: cumulative prospect theory (CPT).

\subsection{A note on prospect theory}

Prospect theory is based on the following five main ideas: reference dependence, declining sensitivity, loss aversion, non-linear weighting of probabilities, and susceptibility to framing effects. Unlike EUT where the carriers of utility are final levels of wealth (or incomes or commodities), under prospect theory the carriers of utility are gains and losses relative to some reference point. Declining sensitivity means that the utility function is concave in the domain of gains and convex in the domain of losses. Loss aversion is based on the idea that losses are more salient than gains. Given an amount of money, $x>0$, and a utility

\footnotetext{
${ }^{2}$ For a certain class of gambles, orders of risk aversion imposes restrictions on the first and second derivatives of the risk premium term with respect to the tax rate.
} 
function, $v(x)$, (to be specified precisely below) loss aversion implies that $v(x)>-v(-x)$. Agents facing uncertain situations overweight small probabilities but underweight large ones. Finally, agents' preferences are influenced by the way a problem is presented. There is a substantial body of evidence in support of these building blocks of prospect theory; see, for instance, the collection of papers in Kahneman and Tversky (2000).

Prospect theory has been successfully used to explain a range of puzzles in economics, such as the disposition effect, asymmetric price elasticities, elasticities of labour supply that are inconsistent with standard models of labour supply, and the excess sensitivity of consumption to income; see, for example, Camerer (2000).

An important application of prospect theory is to the equity-premium puzzle in finance, which is similar in spirit to the tax evasion puzzle in that both can be formulated in terms of a similar portfolio choice problem. The equity premium puzzle asks the following question. Why are annual real rates of return on stocks, relative to bonds, about 6 percent higher since 1926 when the standard deviation for the two investments equals 0.2 and 0.0 respectively? Using EUT, it is difficult to make sense of this apparently high premium on stocks unless individuals have coefficients of relative risk aversion in excess of 30, which is unrealistic ${ }^{3}$. Benartzi and Thaler (1995) successfully use prospect theory to explain the equity premium puzzle based on loss averse agents who are also myopic in the sense of having limited planning horizons. An obvious parallel with tax evasion is to imagine evasion and compliance as two competing investments and ask why people invest disproportionately large amounts in the latter when returns on the former are so high.

\subsection{A brief literature review of tax evasion using prospect theory}

There is already a literature on the application of prospect theory to the tax evasion problem. The experimental studies of Alm et al. suggest that one possible explanation for why people pay taxes might be based on prospect theory. They conjecture that taxpayers might be using a non-linear transformation of probabilities to overweight the probability of a tax audit, which provides an obvious deterrent to tax evasion activity. However, they do not attempt to formalize their suggestion.

A number of papers apply prospect theory to the tax evasion problem in an attempt to analyze the role of "advance tax payments" in deterring tax evasion; for instance, see Yaniv (1999) and Elffers and Hessing (1997). This literature typically uses a restricted prospect theory model that, like EUT, is based on objective probabilities but incorporates reference dependence and loss aversion ${ }^{4}$. To see the intuition behind these models, suppose

\footnotetext{
${ }^{3}$ Mankiw and Zeldes (1991) calculate that a coefficient of relative risk aversion of 30 implies that the certainty equivalent of the prospect - win 50,000 or 100,000 each with probability $1 / 2$ is only 51,209 . This is an absurdly high degree of risk aversion.

${ }^{4}$ The use of "choice heuristics" in this literature (for instance, see Yaniv), to combine common terms in
} 
that the advance tax payments exceed actual tax liability. In this case, by correctly reporting income the taxpayer gets a refund, a gain. Under prospect theory, the taxpayer's utility function is concave for gains. On the other hand, if the advance tax payment were lower than actual tax liabilities, then by subsequently reporting additional income the taxpayer would owe taxes to the government, a loss. Under prospect theory the taxpayer's utility function is convex for losses ${ }^{5}$ and thus might be more willing to take the gamble of evading taxes. Therefore, the level of obligatory advance tax payments can complement the deterrence ability of the tax authorities.

Bernasconi and Zanardi (2004) apply cumulative prospect theory to tax evasion by considering a "general" reference point. There are two states of the world, "income is audited' and 'income is not audited'. In their setting, it is possible for the tax evader to be in the domain of gains or in the domain of losses in both states of the world (see Figure 4.1). In these two cases, as Eide showed, the paradoxical comparative static results of the Allingham-Sandmo-Yitzhaki model carry over to RDEU. Therefore, the only interesting case is that in which the tax payer is in the domain of gains if not caught but in the domain of losses if caught. In this paper, we show that this will be the case if, and only if, the reference point is the legal after-tax income. Hence, we argue the case for a "unique" reference point. Our paper also differs from theirs in several other respects. First, they use a special case of prospect theory where probabilities are transformed as in RDEU. According to Prelec (1998), this is empirically rejected. On the other hand, our application of CPT is standard. Second, they use a fixed probability of detection while we allow the probability of detection to depend on the amount of income evaded. Third, we introduce stigma costs of evasion. Fourth, using parameters estimated by the experimental literature, we show that relative to EUT, prospect theory provides a much better explanation of tax evasion.

\subsection{Our paper and results}

The main objective of the paper is to see if it is possible to resolve the tax evasion puzzles, 1-3 above, using prospect theory ${ }^{6}$.

Stigma from the detection of tax evasion is recognized as an important factor in the tax evasion literature within the EUT framework; see, for example, Skinner and Slemrod

income arising in different states of nature is not consistent with the cumulative prospect theory model of Tversky and Kahneman (1992) that we use in our paper. It instead draws its inspiration from an earlier version of the prospect theory model due to Kahneman and Tversky (1979).

${ }^{5}$ In prospect theory, the attitude to risk is more complex than under EUT, being the result of the interaction of the shape of the utility function, loss aversion and the non-linear weighting of probabilities. This is summarized by the fourfold pattern of attitudes to risk in Tversky and Kahneman.

${ }^{6}$ The tax evasion puzzle (4) is readily explained using prospect theory. Since this has already been done, for example, by Yaniv, we do not address this question any further. It can, however, be incorporated within our framework. 
(1985), Gordon (1989), Besley and Coate (1992). We integrate stigma from tax evasion within a prospect theory framework. Including stigma does not change the comparative static results of our model, but it allows us to predict the level of aggregate tax evasion. Furthermore, we show that the introduction of stigma within EUT does not enable it to resolve tax evasion puzzles 1 and 2, above.

Our results show that EUT, applied to tax evasion, provides several misleading qualitative as well as quantitative predictions that are refuted by the data. Furthermore, the predictions of prospect theory are consistent with the evidence. Using calibration exercises we show that the main quantitative problem with an EUT analysis of tax evasion is that it vastly over-predicts the extent of tax evasion. In contrast, the predicted extent of evasion under prospect theory is consistent with the evidence. The main qualitative problem with an EUT analysis of tax evasion is that it provides a misleading account of the effect of the tax rate on the amount evaded (see the Yitzhaki puzzle above). We show that under prospect theory, an increase in the tax rate is predicted to increase the amount evaded, which is in agreement with the bulk of the evidence. Furthermore, our calibration results show that under EUT the Yitzhaki puzzle remains even in the presence of stigma.

In conjunction, these results strongly suggest the superiority of prospect theory over EUT as a framework in the policy analysis of tax evasion.

Convexity of the value function for losses is the most important element of prospect theory for the explanation of the Yitzhaki puzzle. However, the other elements, loss aversion and non-linear weighting of probabilities, as well as stigma, all play their part in arriving at a good empirical fit. It is important to note that we do not select our parameter values to get a good fit. Quite the contrary; the parameters of our model come from independent experimental evidence, unrelated to the specific problem of tax evasion. When such parameters are not available, we conduct an extensive robustness analysis of our results. Thus, our paper argues, on the one hand, that prospect theory can provide a satisfactory explanation of tax evasion, and, on the other hand, also that the phenomenon of tax evasion provides independent confirmation of prospect theory.

The plan of the paper is as follows. Section 2 describes the basic model. Section 3 considers tax evasion under EUT. Section 4 considers tax evasion under prospect theory. Section 5 calibrates the models under EUT and prospect theory, and Section 6 undertakes a robustness analysis of the results. Finally, Section 7 concludes. All proofs are collected in the appendix available on the JEBO website.

\section{The model}

A taxpayer has exogenous taxable income $W>0$ and can choose to declare some amount $D \in[0, W]$. The government levies a tax on declared income at the constant marginal 
rate $t, 0<t<1$. If the taxpayer evades $(0 \leq D<W)$, then he is caught with probability $p(D) \in[0,1]^{7}$. We assume that $p(D)$ is continuously differentiable and $p^{\prime}(D) \leq 0$ (i.e. the taxpayer is more likely to be caught if he evades more). That the probability of detection may depend on the amount evaded is quite familiar from the tax evasion literature within the EUT framework; see, for example, Slemrod and Yitzhaki. However, to the best of our knowledge, this is the first paper in the prospect theory literature to allow the probability of detection to depend on amount evaded.

If caught, the dishonest taxpayer must pay the outstanding tax liabilities $t(W-D)$, a penalty $\lambda t(W-D)$ where $\lambda>0$ is the penalty rate on evaded taxes and also suffers some stigma $s(W-D)$ where $s$ is the stigma rate on evaded income ${ }^{8}$. There is a continuum of individuals with stigma rates $s \in[\underline{s}, \bar{s}]$ with density $\phi(s)$ and distribution function $\Phi(s)$. Denoting by $Y_{C}$ and $Y_{N C}$, respectively, the income of the taxpayer when he is "caught" and when he is "not caught",

$$
\begin{gathered}
Y_{N C}=W-t D \\
Y_{C}=(1-t) W-(s+\lambda t)(W-D) .
\end{gathered}
$$

\section{Tax evasion under expected utility theory}

Assume that the taxpayer has a strictly increasing, strictly concave and twice continuously differentiable utility function, $u(Y)$. His expected utility is

$$
U(D ; t, s, \lambda, W)=p(D) u\left(Y_{C}\right)+[1-p(D)] u\left(Y_{N C}\right)
$$

Since $U(D ; t, s, \lambda, W)$ is a continuous function of $D$ on the non-empty compact interval $[0, W]$, it attains a maximum at some $D^{*}(t, s, \lambda, W) \in[0, W]$.

\footnotetext{
${ }^{7}$ There are two issues regarding $p(D)$. First, the audits carried out by the tax authorities need not be random. Andreoni et al. mention that for the US, the IRS assigns each tax return a "score" based on a "discriminant function". However, because the score and the discriminant function are strictly private information to the IRS, thus, from the perspective of the taxpayer, her return is randomly audited. Second, for a significant percentage of the population, income taxes are withheld at source, so tax evasion is not an option for them. Suppose, for the sake of argument, that this applies to half the population. In that case the effective probability of audit doubles for taxpayers whose income is not withheld at source. In the US, for instance, where the probability of an audit is about 1.5 percent (see Andreoni et al.) the effective probability of an audit is then about 3 percent and possibly no more than 5 percent (see Skinner and Slemrod). Our simulation results compare EUT and Prospect Theory for probabilities in this range.

${ }^{8}$ As in Gordon (1989) and Besley and Coate (1992), such stigma enters linearly, as a monetary equivalent, into the payoff in that state of the world. Stigma costs could arise from factors such as social sanctions and the effect on one's current and future earnings arising from being a tax evader. We discuss issues about the magnitude of stigma, a more general formulation of stigma, and "guilt" that might arise from the act of evasion in Section 5
} 


\section{Proposition 1 Under EUT,}

(a) At a regular interior optimum, tax evasion is strictly decreasing in the punishment rate (per dollar of evaded tax), $\lambda$, and the stigma rate (per dollar of concealed income), $s$.

(b) At an optimum on the boundary $\left(D^{*}=0\right.$ or $\left.D^{*}=W\right)$, tax evasion is non-increasing in the punishment rate (per dollar of evaded tax), $\lambda$, and the stigma rate (per dollar of concealed income), $s$.

(c) However, the effect of a change in the tax rate, $t$, on tax evaded is ambiguous.

The result that tax evasion is decreasing in the punishment rate and the stigma rate is in agreement with intuition and evidence ${ }^{9}$. However, extra assumptions are needed to determine the effect of a change in the tax rate on tax evaded, which we turn to next.

\subsection{Y itzhaki's puzzle}

Proposition 2 Assume that the probability of detection is independent of the amount evaded, so $p^{\prime}(D)=0$. Also assume no stigma $(s=0)$ and non-increasing absolute risk aversion. Under these conditions, EUT predicts

(a) At an interior optimum an increase in the tax rate, $t$, causes a reduction in tax evaded.

(b) At an optimum on the boundary $\left(D^{*}=0\right.$ or $\left.D^{*}=W\right)$, tax evasion is non-increasing in the tax rate, $t$.

This result was first obtained by Yitzhaki. The intuition can be given by imagining evasion and reporting as two distinct activities. With $\lambda>0$, evasion becomes more expensive, relative to non-evasion, as $t$ increases. However, an increase in $t$ reduces the income of the taxpayer. With constant or declining absolute risk aversion, this induces the agent to reduce the risky activity (i.e. evasion). Hence, on both counts evasion falls with an increase in the tax rate. On the other hand, the bulk of empirical and experimental evidence, some of which is reviewed in the introduction, is suggestive of the contrary effect (i.e. evasion increases as taxes increase ${ }^{10}$ ).

\section{Tax evasion under prospect theory}

From Proposition 1 we saw that, at a quite general level, expected utility theory fails to predict the direction of the response of tax evasion to a change in the tax rate. Under the more restrictive assumptions of Proposition 2, expected utility theory makes a definite

\footnotetext{
${ }^{9}$ If labor income is endogenous, then $\lambda$ impacts the effective wage rate. Because the wage rate has opposing income and substitution effects on labor supply, the effect is no longer unambiguous; see Andreoni et al.

${ }^{10}$ Recall point 3 of the introduction.
} 
prediction, but this prediction is rejected by the bulk of the empirical evidence. We now show that prospect theory makes the empirically correct comparative-static predictions, namely, that the amount of tax evaded declines with a rise in the punishment and stigma rates, $\lambda$ and $s$, respectively, and increases with an increase in the tax rate, $t$.

\subsection{Utility of an outcome under prospect theory}

Let $R$ be the reference income of the taxpayer, and let the income relative to this reference point be

$$
X_{i}=Y_{i}-R
$$

where $i=C$ or $N C$ denotes the two states "caught" and "not caught". As in Tversky and Kahneman, the utility associated with a gain or loss $X_{i}$ is $v\left(X_{i}\right)$, and

$$
v\left(X_{i}\right)=\left\{\begin{array}{ccc}
X_{i}^{\beta} & \text { if } & X_{i} \geq 0 \\
-\theta\left(-X_{i}\right)^{\beta} & \text { if } & X_{i}<0
\end{array}\right.
$$

where $\beta \in[0,1]$ and $\theta>1$ are preference parameters and $v$ is called the value function. Tversky and Kahneman stated that the power form given in (4.2) arises from the axiom of preference homogeneity ${ }^{11}$. The parameter $\theta$ is the parameter of loss aversion; it encapsulates the basic idea that a loss of $x$ dollars is more painful than the pleasure derived from a gain of $x$ dollars. Based on experimental evidence, Tversky and Kahneman suggest that $\beta \mathrm{u} 0.88$ while $\theta \mathrm{u} 2.25 .^{12}$ The graph in Figure 4.1 is sketched for $\beta=0.5$.

\subsection{The reference point under prospect theory}

Although prospect theory does not provide sufficient guidance to determine the reference point in each possible situation, in several cases there can be a plausible candidate for a reference point. Indeed, specifying a suitable reference point is often essential for a successful application of prospect theory.

We take the legal after-tax income as the reference point in this paper, so

$$
R=(1-t) W
$$

This has the implication that if the taxpayer evades but is not caught, then she finds herself in the domain of gains. On the other hand, if she evades and is caught, then she

\footnotetext{
${ }^{11}$ Consider a lottery $\left(x_{1}, \ldots, x_{n} ; p_{1}, \ldots, p_{n}\right)$ that gives prize $x_{i}$ with probability $p_{i}$. Preference homogeneity requires that $\left(x_{1}, \ldots, x_{n} ; p_{1}, \ldots, p_{n}\right) \sim y \Rightarrow\left(k x_{1}, \ldots, k x_{n} ; p_{1}, \ldots, p_{n}\right) \sim k y$, where $\sim$ is the indifference relation.

${ }^{12} \mathrm{As}$ in other areas of economics, specific functional forms and parameter values are needed for calibration exercises. The functional form given in (4.2) is consistent with experimental evidence, and has an axiomatic basis. The values for $\theta$ and $\beta$ are drawn from a wide range of experimental evidence unrelated to the problem of tax evasion.
} 


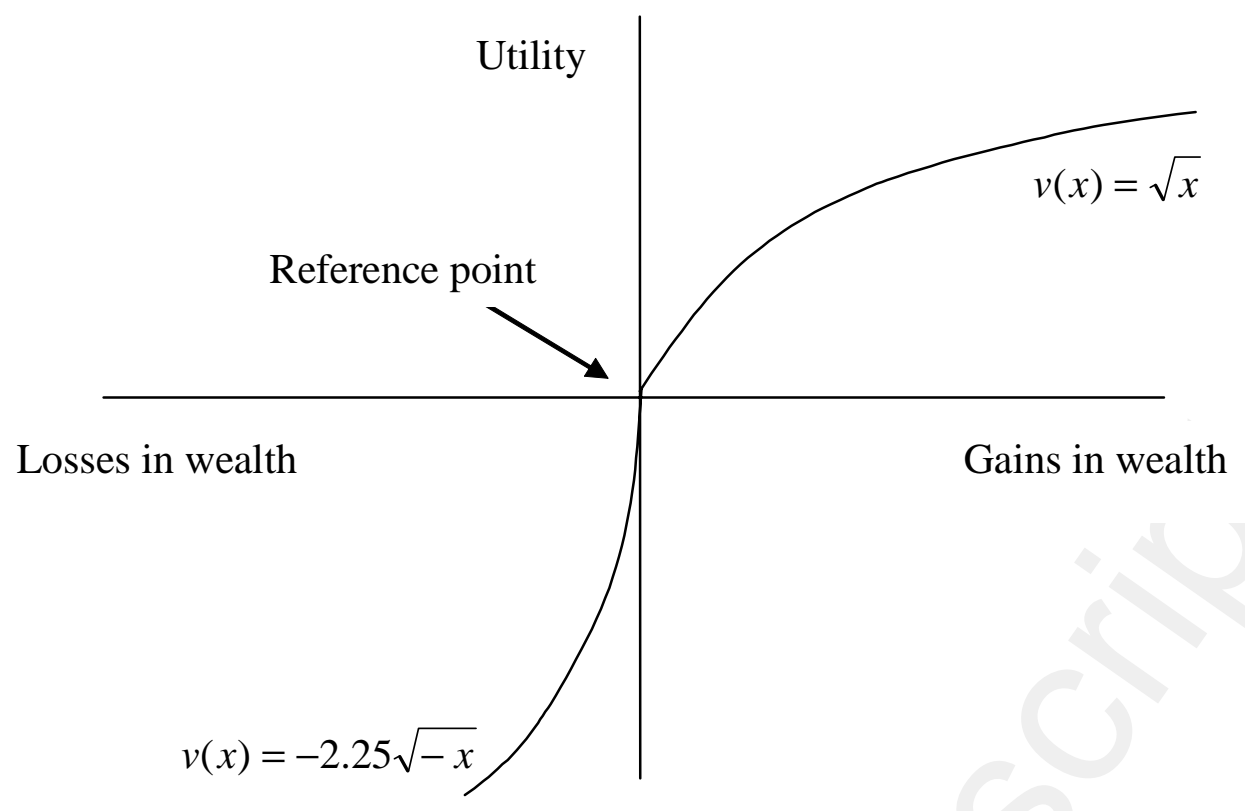

Figure 4.1: Preferences Under P rospect Theory

finds herself in the domain of losses ${ }^{13}$.

We justify (4.3) as follows. If the taxpayer is always in the domain of gains or always in the domain of losses, then CP reduces to RDEU. But Eide showed that the paradoxical comparative static results of the Allingham-Sandmo-Yitzhaki model carry over to RDEU. Therefore, the only interesting case is that in which the tax payer is in the domain of gains if not caught but in the domain of losses if caught. Proposition 3, below, shows that this will be the case if, and only if, the reference point is the legal after tax income (4.3). ${ }^{14}$

Proposition 3 Suppose that for all levels of declared income, $D \in[0, W]$, a tax payer is in the domain of gains if not caught, $X_{N C} \geq 0$, but in the domain of losses if caught, $X_{C} \leq 0$. Then the reference point must, necessarily, be $R=(1-t) W$.

\footnotetext{
${ }^{13}$ There is an old adage in public finance that says that "an old tax is a good tax". An even stronger version of this adage is that "an old tax is no tax"; see, for instance, Bastable (1892, Book III, Chapter VII.18) or Needham $(2002, \mathrm{p} 6)$. What these adages imply is that the current legal tax liabilities are "salient" in the sense of providing an individual with a focal or a reference point. Hence, a tax cut would be coded as a gain while a tax increase would be coded as a loss.

${ }^{14}$ As pointed out by a referee, it is sufficient that the taxpayer is in the domain of gains if not caught and in the domain of losses if caught for the actual level of declared income. However, to guarantee that this is the case, we have assumed that it holds for all possible levels of declared income.
} 


\subsection{The probability weighting function}

There is considerable empirical evidence that people overweight low probabilities but underweight high probabilities; see, for example, Kahneman and Tversky (1979), Tversky and Kahneman (1992) and Starmer (2000). We take a probability weighting function to be a strictly increasing function, $w(p)$, from $[0,1]$ onto $[0,1]$. Hence $w(p)$ is continuous with $w(0)=0, w(1)=1$. We assume that $w(p)$ is differentiable on $(0,1)$. At a general leve ${ }^{15}$, the probability weighting function for gains, $w^{+}(p)$, need not be the same as that for losses, $w^{-}(p)$. We illustrate in Figure 5.1 an example of a specific weighting function, due to Prelec.

\subsection{The tax evasion decision under prospect theory}

Recall that our reference income is legal after-tax income (4.3): $R=(1-t) W$. Hence, from (4.1), $X_{N C}=Y_{N C}-(1-t) W$ and $X_{C}=Y_{C}-(1-t) W$. Then, using (2.1), (2.2) and recalling that $0 \leq D \leq W$, we get

$$
\begin{gathered}
X_{N C}=t(W-D) \geq 0, \\
X_{C}=-(s+\lambda t)(W-D) \leq 0 .
\end{gathered}
$$

Hence, the taxpayer is in the domain of losses if caught but in the domain of gains if not caught. Let $v$ be the taxpayer's value function and $w^{+}, w^{-}$be her probability weighting function for the domains of gains and losses, respectively. Then, according to cumulative prospect theory, the taxpayer maximizes ${ }^{16}$

$$
V(D ; t, s, \lambda, \theta, W)=w^{-}[p(D)] v\left(X_{C}\right)+w^{+}[1-p(D)] v\left(X_{N C}\right) .
$$

Comparing (4.6) with the analogous expression for expected utility theory, (3.1), we see the following differences. First, the carriers of utility in prospect theory are gains and losses relative to some reference point rather than levels. Second, one uses decision weights in prospect theory to aggregate outcomes while one uses objective probabilities under expected utility theory. From (4.2), (4.4), (4.5) and (4.6) we get

$$
V(D ; t, s, \lambda, \theta, W)=[t(W-D)]^{\beta} w^{+}[1-p(D)]-\theta[(s+\lambda t)(W-D)]^{\beta} w^{-}[p(D)] .
$$

Letting

$$
h(D ; t, s, \lambda, \theta)=t^{\beta} w^{+}[1-p(D)]-\theta(s+\lambda t)^{\beta} w^{-}[p(D)],
$$

\footnotetext{
${ }^{15}$ We are grateful to a referee for reminding us of this.

${ }^{16}$ Bernasconi and Zanardi set $w^{+}(1-p)=1-w^{-}(p)$. However, to quote from Prelec (last line of Appendix A): "CPT reduces to RDU if $w^{-}(p)=1-w^{+}(1-p)$. Empirically, however, one observes $w^{+}(p)=w^{-}(p)$." Therefore, in our calibration exercises, we shall take $w^{+}(p)=w^{-}(p)$.
} 
we get that (4.7) can be written in the following form:

$$
V(D ; t, s, \lambda, \theta, W)=(W-D)^{\beta} h(D ; t, s, \lambda, \theta) \text {. }
$$

Since $V(D ; t, s, \lambda, \theta, W)$ is a continuous function on the non-empty compact interval $[0, W]$, it attains a maximum at some point $D^{*}(t, s, \lambda, \theta, W) \in[0, W]$.

Proposition 4 Under prospect theory,

(a) At a regular interior optimum, tax evasion is strictly decreasing in the punishment rate, $\lambda$, the stigma rate, $s$, and the coefficient of loss aversion, $\theta$. However, tax evasion is strictly increasing in the tax rate, $t$.

(b) At an optimum on the boundary $\left(D^{*}=0\right.$ or $\left.D^{*}=W\right)$, tax evasion is non-increasing in the punishment rate, $\lambda$, the stigma rate, $s$, and the coefficient of loss aversion, $\theta$. However, tax evasion is non-decreasing in the tax rate, $t$.

Comparing Proposition 4 with Proposition 1, we see that both EUT and prospect theory predict the empirically correct comparative static results for a change in $\lambda$ and $s$. Furthermore, an increase in loss aversion under prospect theory reduces the taxpayer's payoff when caught, hence reducing the incentive to evade.

While EUT fails to predict the direction of change in the amount of tax evaded when the tax rate changes (see Proposition 1), prospect theory predicts the empirically correct result.

Furthermore, under the conditions of Proposition 2, EUT predicts the empirically wrong result (the Yitzhaki puzzle) while, from Proposition 4, we see that the empirically correct result is predicted by prospect theory. The intuition is that when a tax evader is caught, he finds himself in the domain of losses. Under prospect theory the value function is convex for losses. It follows that an increase in the tax rate causes the taxpayer to be poorer and, hence, more risk seeking, so he evades more.

\section{Model Calibration}

What accounts for the high degree of tax compliance when actual $(\lambda, p)$ combinations are such that $1-p-p \lambda>0$ ? To answer this question, it is useful to start with the following question. Given actual magnitudes of tax evasion in the population, what combinations of $(\lambda, p)$ are required to sustain that level of evasion? Since the weighting function in prospect theory is highly non-linear, analytical answers are not possible. Hence, the analysis below provides simulation results in a calibrated model.

Most, if not all, calibration exercises in tax evasion use a fixed probability of detection; see, for instance, Skinner and Slemrod (1985) and Bernasconi (1998). The reason is that 
one does not know the exact shape of the probability detection schedule. In keeping with this practice we adopt, in this section and the next, the assumption that the probability of detection is fixed. This could be viewed as a simplifying modelling procedure on our part $^{17}$. Alternatively, it could be viewed as an assumption about the behavior of taxpayers. In the absence of concrete information on the shape of the probability detection schedule, a taxpayer may decide to treat the probability of detection as fixed. We summarize the results of our model with a fixed detection probability. Details of derivations and a diagrammatic exposition can be found in Dhami and al-Nowaihi (2005).

\subsection{Model results with a fixed detection probability}

\subsubsection{Expected Utility Theory}

To facilitate comparison with prospect theory, take $U(Y)=Y^{\beta}$ when $Y \geq 0$ and $U(Y)=0$ when $Y<0$. Differentiating (3.1) gives

$$
\frac{\partial E[U]}{\partial D}=-t \beta(1-p)\left[Y_{N C}\right]^{\beta-1}+p \beta[t \lambda+s]\left[Y_{C}\right]^{\beta-1}
$$

where $Y_{C}$ and $Y_{N C}$ are defined in (2.1) and (2.2) respectively. The second order condition can be easily checked to be satisfied. Hence, the necessary and sufficient condition for the maximization of expected utility in the region $Y_{C}>0$, is given by

$$
\begin{gathered}
\frac{\partial E[U]}{\partial D} \geq 0 \text { for } D=W \\
\frac{\partial E[U]}{\partial D}=0 \text { for } 0<D<W \\
\frac{\partial E[U]}{\partial D} \leq 0 \text { for } D=0 .
\end{gathered}
$$

If the taxpayer does not evade $(D=W)$ then $Y_{C}=Y_{N C}=W-t D>0$ and, hence, (5.1), and the first row of (5.2) apply. In particular, $\frac{\partial E[U]}{\partial D} \geq 0$ gives $-t(1-p)+p[t \lambda+s] \geq$ 0 and, hence,

$$
\lambda \geq \frac{1-p}{p}-\frac{s}{t}
$$

In $(\lambda, p)$ space, $(5.5)$ gives the set of $(\lambda, p)$ points such that a taxpayer with stigma $s \in[\underline{s}, \bar{s}]$ reports the full amount of income. At all points below this set, the taxpayer chooses to evade some strictly positive fraction of income. From (5.2) - (5.5) it can be checked that at $D=W$ there exists some critical value of stigma $s_{c}$ such that

$$
\lambda(p)=\frac{1-p}{p}-\frac{s_{c}}{t} .
$$

\footnotetext{
${ }^{17}$ Even in macroeconomics where calibration is most prevalent, despite the non-linearities it is usually the simplified log-linearized version of the model that is used in the calibration exercises.
} 
From (5.2) - (5.4) and (5.6) it can be checked that

$$
\frac{\partial E U}{\partial D}<0 \text { for } s<s_{c} ; \frac{\partial E U}{\partial D}=0 \text { for } s=s_{c} ; \frac{\partial E U}{\partial D}>0 \text { for } s>s_{c} .
$$

We summarize this result below.

Proposition 5 There is some critical level of stigma $s_{c}$, defined by the relation $\lambda(p)=$ $\frac{1-p}{p}-\frac{s_{c}}{t}$, such that if $s \geq s_{c}$ then $D=W$. For any $s<s_{c}, D<W$.

In the absence of stigma costs (i.e. $s=0),(5.5)$ implies that the taxpayer will evade some fraction of income when

$$
1-p-p \lambda>0
$$

as claimed in the opening paragraph of the introduction.

Solving (5.3), the interior solution to the declared income is given by

$$
D=W\left[1-(1-t)\left[(t \lambda+s)+t\left(\frac{(t \lambda+s) p}{t(1-p)}\right)^{\frac{1}{1-\beta}}\right]^{-1}\right]
$$

All the usual comparative static results under expected utility can be checked directly from (5.8).

\subsubsection{Prospect Theory}

Putting a fixed detection probability in (4.8), we get that

$$
h(t, s, \lambda, \theta)=t^{\beta} w^{+}(1-p)-\theta(s+\lambda t)^{\beta} w^{-}(p) .
$$

Hence, (4.9) can be written in the form

$$
V(D ; t, s, \lambda, \theta, W)=(W-D)^{\beta} h(t, s, \lambda, \theta) .
$$

Since the value equation in (5.10) is monotonic in $D$, the solution is

$$
\begin{aligned}
& \text { Case-I: } \quad D=0 \quad \text { if } \quad h>0 \Rightarrow\left(\frac{1}{\theta}\right) \frac{w^{+}(1-p)}{w^{-}(p)}>\left(\lambda+\frac{s}{t}\right)^{\beta} \\
& \text { Case-II: } \quad D \in[0, W] \quad \text { if } \quad h=0 \Rightarrow\left(\frac{1}{\theta}\right) \frac{w^{+}(1-p)}{w^{-}(p)}=\left(\lambda+\frac{s}{t}\right)^{\beta} \\
& \text { Case-III: } \quad D=W \quad \text { if } \quad h<0 \Rightarrow\left(\frac{1}{\theta}\right) \frac{w^{+}(1-p)}{w^{-}(p)}<\left(\lambda+\frac{s}{t}\right)^{\beta} \text {. }
\end{aligned}
$$

The solution to the tax evasion problem under prospect theory, when the probability of detection is fixed, is a bang-bang solution. We would argue that the bang-bang solution seems descriptive of several forms of tax evasion that take the form of hiding certain activities completely from the tax authorities while fully declaring other sources. For instance, an academic might not report income arising from an invited but paid lecture. 
A school teacher might not report tuition income for after-school lessons. A householder might pay cash to a builder for a minor extension of the house. Line item reporting of tax returns might further encourage this behavior. This bang-bang implication of reporting taxable income can also be drawn from the experimental results of Pudney et al. (2000). Slemrod and Yitzhaki find, based on TCMP data for 1988, that "the voluntary reporting percentage was $99.5 \%$ for wages and salaries, but only $41.4 \%$ for self-employment income". Additional support comes from the behavior of non-profit organizations whose profits from activities unrelated to their primary tax exempt purpose are subject to federal and state tax. The reporting behavior of such organizations is suggestive of the bang-bang solution; see Omer and Yetman (2002).

Define

$$
s_{c}=t\left[\frac{w^{+}(1-p)}{\theta w^{-}(p)}\right]^{1 / \beta}-t \lambda .
$$

From (5.11) the following result is obvious and we state it without proof.

Proposition 6 Ceteris-paribus $\exists s=s_{c} \in[\underline{s}, \bar{s}]$, such that, when $s>s_{c}$, where $s_{c}$ is defined by (5.12), the taxpayer declares the full amount of income, while in the complementary case, all income is evaded.

\subsection{Parameter Values for Calibration Results}

From estimates in Tversky and Kahneman we know that $\beta \approx 0.88$ and $\theta \approx 2.25$. We use a tax rate of 30 percent (i.e. $t=0.3$ ). From Andreoni et al., we know that in actual practice about 40 percent of taxpayers report their incomes incorrectly in the US ${ }^{18}$; see also Bernasconi. Since these figures include those who unintentionally report incorrectly, we use the more conservative estimate that only about 30 percent evade taxes.

While most parameters necessary for the calibration exercise are readily available, the incorporation of stigma in calibration exercises is less than straightforward. Evidence suggests that the stigma arising from tax evasion is of a very small magnitude; for instance, see Brooks (2001). There are several possible reasons for this. First, information on the identity of tax evaders is not usually in the public domain; hence, social ostracization is likely to be small. Second, individuals might feel relatively more guilty about cheating other individuals as compared to the government, which can be perceived to be an inanimate entity $^{19}$. Third, stigma is likely to be felt only from events arising in the future. Thus, in

\footnotetext{
${ }^{18}$ Citing evidence from TCMP (taxpayer compliance measurement program) data, Andreoni et. al. mention that for 1998, 40 percent of US households underpaid taxes. It is estimated that about 7 percent of the households unintentionally underpaid, so approximately a third of the households evade. A quarter of all households underpaid by $\$ 1500$ or more.

${ }^{19}$ Experimental evidence indicates that the subjects of ultimatum game experiments exhibit a much greater regard for others (70-30 splits are not uncommon) relative to the predictions of economic theory.
} 
an appropriate dynamic game (which we do not model), if individuals have current-biased preferences, they are likely to underweight these future costs (over and above that arising from normal exponential discounting) ${ }^{20}$.

While the general view seems to be that stigma costs from evasion are low, we are not aware of the exact magnitudes. Some evidence is available from stigma costs that arises from claiming welfare benefits. Pudney et al. (2002) find that the total stigma costs (which they define as stigma, hassle, search costs, etc.) come to no more than $£ 2-£ 4$ per week, where the average benefit level in the sample is about $£ 21$ per week. As a percentage of welfare benefits, stigma costs range from about 10-20 percent.

We assume that the stigma rate from the detection of tax evasion is distributed uniformly over the unit interval (i.e. $s \in[0,1]$ ). Several factors motivate this choice. First, stigma costs from the detection of tax evasion are likely to be larger than those arising from welfare benefits. Even if we allow for the maximum stigma rate to be up to 5 times higher (relative to the maximum that arises from the receipt of welfare payments), its magnitude is still less than 1 . Second, restricting $s$ to the domain $[0,1]$ allows for the stigma rate to be interpreted as a "social tax" from engaging in illicit activity that lies between one and a hundred percent. Third, we perform a robustness analysis of the stigma rate below that bears out our results.

From Propositions 5 and 6 , we know that all individuals characterized by $s>s_{c}$ do not evade taxes while all those with $s<s_{c}$ evade taxes. Given $s \in[0,1]$, the stylized fact that approximately 30 percent of taxpayers evade taxes corresponds to

$$
s_{c}=0.3
$$

which is the value we shall use for the calibration exercise.

\subsection{Calibration Results}

We ask the following question. Given realistic magnitudes of tax evasion (i.e. 30 percent), how close are the predicted $\lambda, p$ values under EUT and prospect theory, respectively, to their actual values ${ }^{21}$ ?

Under expected utility, using Proposition 5, (5.13) and the calibration values specified above, the locus of $(\lambda, p)$ combinations that need to be consistent with the actual data is given by

However, when individuals play the ultimatum game against inanimate objects such as computers, they behave as predicted by economic theory (100-0 splits are not uncommon); for instance, see Camerer et al. (2004).

${ }^{20}$ This is likely to arise if in an appropriately specified dynamic model, the taxpayers have hyperbolic preferences; for instance, see Camerer et al. (2004).

${ }^{21}$ We could have posed our question in many different, but equivalent ways. For example, given actual $(\lambda, p)$ combinations, what level of tax evasion does each theory predict? 


$$
\lambda^{E U}(p)=\frac{1-p}{p}-\frac{0.3}{0.3}
$$

where superscript $E U$ refers to 'expected utility'.

\subsubsection{The Prelec probability weighting function}

For our calibration exercise we adopt the weighting function of Prelec ${ }^{22}$ because it is parsimonious, consistent with much of the available empirical evidence and has an axiomatic foundation ${ }^{23}$. The Prelec weighting function has the following form:

$$
w^{+}(p)=w^{-}(p)=w(p)=e^{-(-\ln p)^{\alpha}} \text { for } p \in(0,1], w(0)=0 \text { and } 0<\alpha<1 .
$$

Note that $w(p)$ is a strictly increasing function from $[0,1]$ onto $[0,1], w(0)=0, w(1)=1$, $w\left(e^{-1}\right)=e^{-1} \simeq 0.37, w(p)$ is strictly concave on $\left(0, e^{-1}\right)$ with $w(p)>p, w(p)$ is strictly convex on $\left(e^{-1}, 1\right)$ with $w(p)<p$, and $w(p)$ is $C^{\infty}$ on $(0,1)$ (see Figure 5.1).

Using (5.11), (5.12), (5.13) and the Prelec weighting function (5.15), the $(\lambda, p)$ locus under prospect theory is given by

$$
\lambda^{P T}(p)=\left(\frac{1}{2.25}\right)^{\frac{1}{0.88}} \Gamma(p)^{\frac{1}{0.88}}-\frac{0.3}{0.3},
$$

where the superscript $P T$ refers to 'prospect theory' and

$$
\Gamma(p)=\exp \left[(-\ln p)^{0.35}-(-\ln (1-p))^{0.35}\right] \text {. }
$$

We have substituted the value of $\alpha=0.35$ in $\Gamma(p)$. This is not restrictive; for robustness analysis, see Section 6 below.

In Figure 5.2, the horizontal axis represents the audit probability $p$, and the vertical axis represents the audit penalty, $\lambda$. Since most realistic audit probabilities are in the

${ }^{22}$ Tversky and Kahneman proposed the following probability weighting functions, for the domain of gains and losses respectively:

$$
\begin{array}{ll}
w^{+}(\mathbf{p})=\mathrm{p}^{\gamma}\left\{\mathbf{p}^{\gamma}+(1-\mathrm{p})^{\gamma}\right\}^{-1 / \gamma} ; & \gamma \mathrm{u} 0.61 \\
w^{-}(\mathbf{p})=\mathrm{p}^{\delta}\left\{\mathbf{p}^{\delta}+(1-\mathrm{p})^{\delta}\right\}^{-1 / \delta} ; & \delta \mathrm{u} 0.69
\end{array}
$$

Camerer and Ho propose

$$
f(p)=1-(1-p)^{\gamma} /\left[p^{\gamma}+(1-p)^{\gamma}\right]^{1 / \gamma} \text { with } f(0.7) \text { u } 0.7
$$

For an application of this weighting function to tax evasion, see Bernasconi (1998). Our results, however, do not critically depend on which probability weighting function we use.

${ }^{23}$ Prelec gives axiomatic foundations. For alternative axiomatic foundations, see Luce (2001) and alNowaihi and Dhami. 


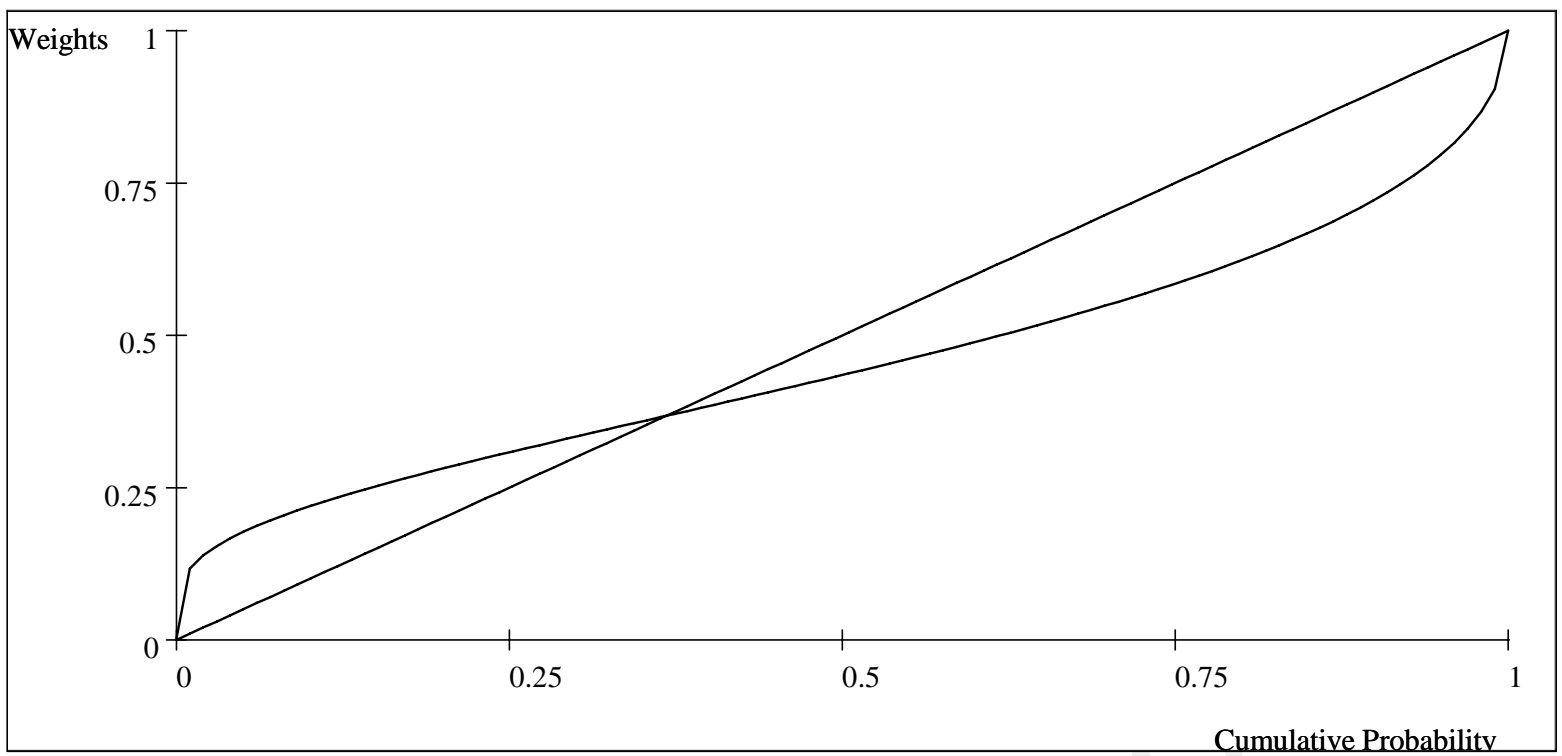

Figure 5.1: A Prelec Weighting Function for $\alpha=0.5$

range 0.01 to 0.03 the horizontal axis is shown up to a maximum value of $0.05 .^{24}$ The upper, thicker curve plots the $(\lambda, p)$ locus for expected utility in (5.14) and the lower, thinner curve plots the $(\lambda, p)$ locus for prospect theory in (5.16). It is clear that the $(\lambda, p)$ locus for EUT is everywhere significantly above that for prospect theory. In Figure 5.2, the vertical axis gives the penalty rate. Hence, a penalty rate of 50 , for instance, means that for each pound of tax evaded, the penalty is 50 pounds. Actual magnitudes of penalty rates range from 50 pence to 2 pounds for every pound evaded.

The numerical magnitudes of $(\lambda, p)$ that correspond to the two loci in the figure are shown in the table below.

Table I: Comparison of $\boldsymbol{\lambda}$ Under Expected Utility and Prospect Theory

\begin{tabular}{|c|c|c|c|c|c|c|c|c|c|c|}
\hline$p$ & .005 & .010 & .015 & .020 & .025 & .030 & .035 & .040 & .045 & .050 \\
\hline$\lambda^{E U}(p)$ & 197.67 & 97.67 & 64.33 & 47.67 & 37.67 & 31.00 & 26.23 & 22.67 & 19.89 & 17.67 \\
\hline$\lambda^{P T}(p)$ & 1.55 & 1.21 & 1.00 & 0.86 & 0.75 & 0.66 & 0.58 & 0.52 & 0.46 & 0.41 \\
\hline
\end{tabular}

$\lambda^{E U}(p)$ and $\lambda^{P T}(p)$ are the predicted penalty rates consistent for a given $p$ and a tax evasion rate of 30 percent under EUT and Prospect theory, respectively. For most realistic

\footnotetext{
${ }^{24}$ Here we follow Skinner and Slemrod (1985): "In 1981 a total of 2 percent of private returns were audited in the United States. While the IRS has established elaborate methods of flagging suspicious returns, it is unlikely that the probability of audit, $p$, for the amateur tax evader exceeds 5 percent depending on the kind of evasion." Suppose that only 2 percent of "suspicious returns" are audited. Even if only taxes are withheld at source for 60 percent of the population (which constitutes the "non-suspicious" returns), the effective probability of audit for for the remaining 40 percent who have an opportunity to evade is no more than 5 percent.
} 


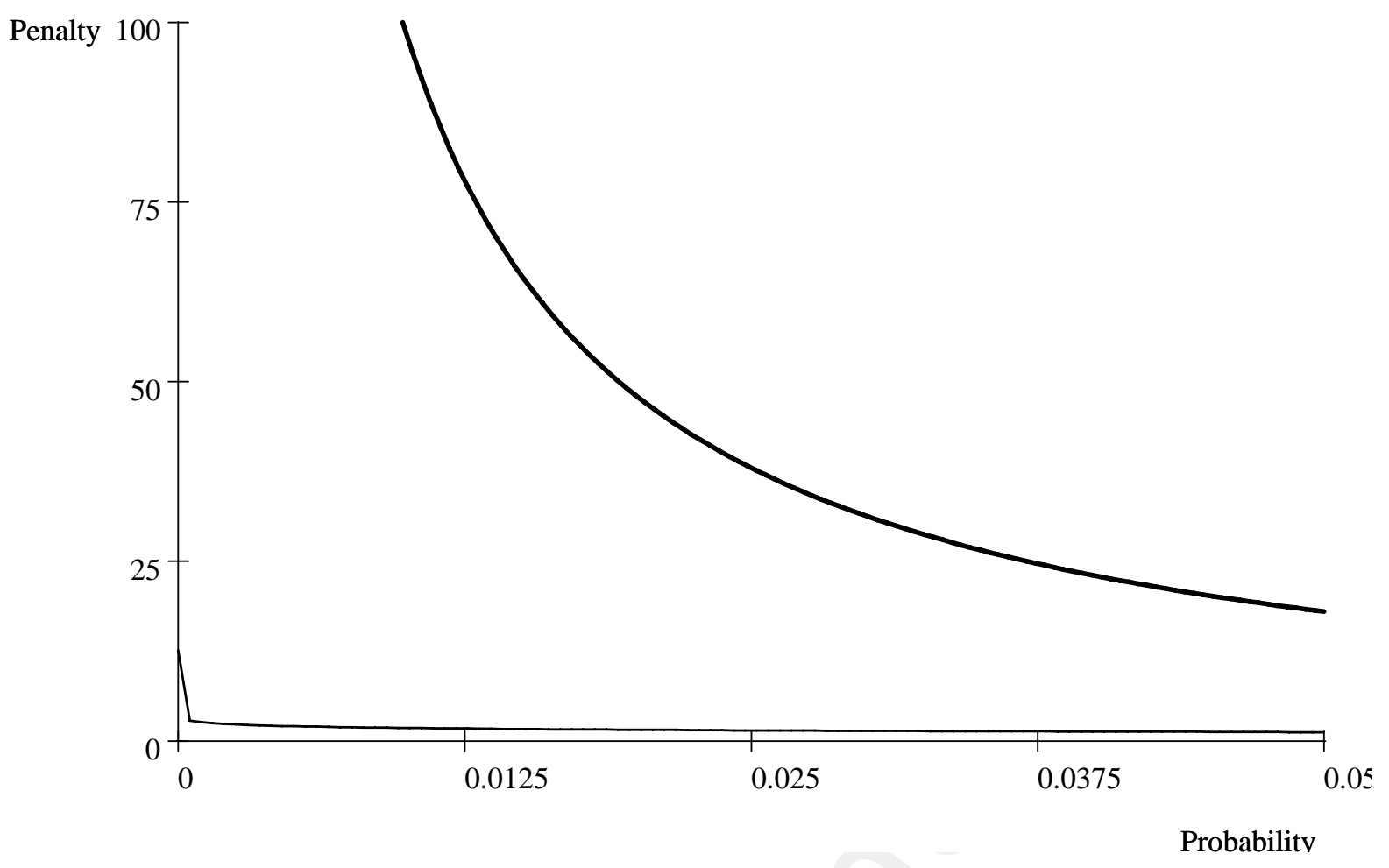

Figure 5.2: $\lambda, p$ values consistent with $30 \%$ tax evasion under EUT and PT.

audit probabilities (i.e. $p \in[0.01,0.03]$ ), the estimate of the penalty rate ranges from 0.66 to 1.21 for Prospect Theory. This is consistent with actual values for the audit probabilities that range from 0.5 in USA to 2.0 in Italy; see Bernasconi for these figures. On the other hand, EUT predicts a penalty rate that is up to 100 times larger in this range and on average about 60 times higher! The above is summarized, without proof, by the following Proposition.

Proposition 7 For realistic magnitudes of tax evasion (approximately 30 percent) and audit probabilities ( 1 to 3 percent), the penalty rate predicted by Prospect theory is 0.66 to 1.21 while that predicted by EUT is 31 to 98 . The penalty rate predicted by Prospect theory is consistent with observed rates.

This provides strong vindication for the choice of prospect theory in explaining actual parameters of policy choice relevant for the tax evasion problem. It is remarkable that the predicted magnitudes of $(\lambda, p)$ are so close to the actually observed values when one considers that the parameter values used for the calibration exercise were obtained from independent experimental evidence applied to generic situations of risk. 


\section{R obustness analysis}

In this section we examine the sensitivity of the results to variations in the magnitude of the weighting parameter, $\alpha$, and the stigma rate, $s$. We also examine the implications of a more general formulation of the stigma rate and the issue of guilt. Unlike stigma, which arises only if the tax-evader is caught, guilt arises from the act of evasion itself, whether the tax-evader is caught or not.

\subsection{Weighting parameter $\alpha$}

The calibration results depend on the value of the parameter $\alpha$ in the Prelec weighting function. An increase in $\alpha$ reduces the degree of overweighting of small probabilities. In particular, $w(p) \rightarrow p$ as $\alpha \rightarrow 1$ (i.e., in the limit, the objective and subjective probabilities coincide). We now examine the robustness of the results with respect to $\alpha$ in Figure 6.1, which plots the $\lambda, p$ locus under prospect theory, (5.16), for successive values of $\alpha=0.3$, $0.4,0.5,0.6$. The $\lambda, p$ locus shifts up monotonically as $\alpha$ increases (so the lowest locus corresponds to $\alpha=0.3$ and the highest corresponds to $\alpha=0.6$ ).

To see if the $\lambda, p$ loci are reasonable, we have drawn horizontal lines in Figure 6.1 corresponding respectively to the values $\lambda=0.5, \lambda=2.0$ and $\lambda=4.0$. While the official penalty rate seems to vary between $\lambda=0.5$ and $\lambda=2.0$, there are other, potentially important costs to an individual when tax evasion is discovered that increase the "effective penalty rate" ${ }^{15}$. The $\lambda=4.0$ bound might not be unreasonable in light of these costs. Finally, and taking the suggestion of Skinner and Slemrod, Figure 6.1 is plotted for audit probabilities that lie between 1 to 5 percent.

It can be seen from Figure 6.1 that the $\lambda, p$ loci for prospect theory lie roughly within the expected range. Hence, while the results are sensitive to $\alpha$, they are nevertheless within reasonable bounds.

\subsection{Stigma rate, $s$}

Recall that a stigma rate from tax evasion of up to 5 times higher than the maximum arising from receipt of welfare payments gave rise to $s_{c}=0.30$. The literature points to low levels of stigma from evasion. For robustness purposes, suppose that we allowed for stigma rates such that the critical value, $s_{c}$, respectively halved and doubled ${ }^{26}$. It turns out that there is only a small change in the predicted value of $\lambda$ (by -0.5 and

\footnotetext{
${ }^{25}$ These costs do not have the nature of stigma costs. Of particular importance could be the possibly high monetary costs arising on account of legal expenses. Even if one decides not to pursue the accusation in a court, one often needs to incur the cost of legal advice to make that decision. Other, plausible costs include the loss of income, hassle and inconvenience costs etc.

${ }^{26}$ In other words, $s \sim U[0,0.5]$ and $s \sim U[0,2.0]$ respectively, which implies that $s_{c}=0.15$ and $s_{c}=0.60$ respectively.
} 


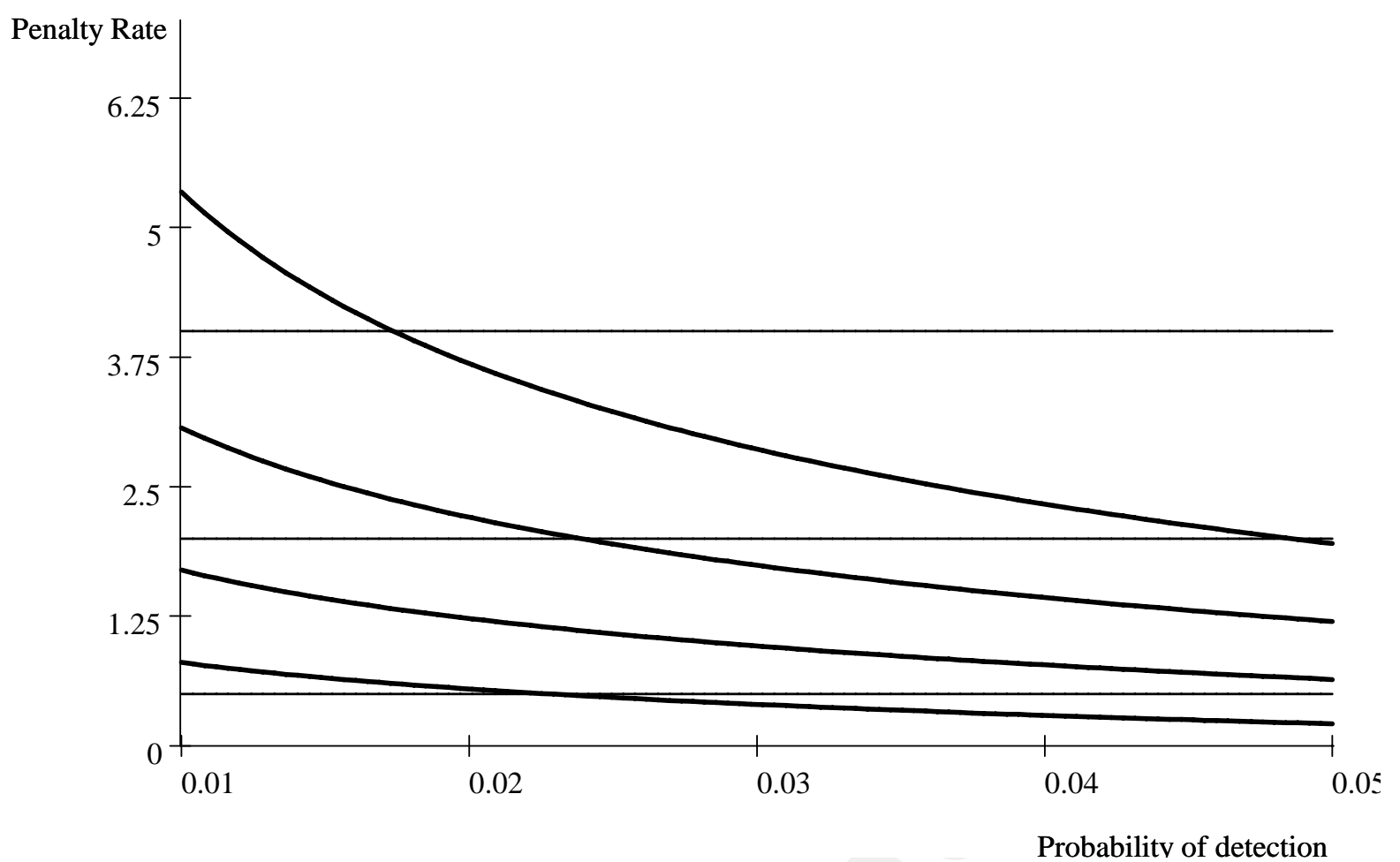

Figure 6.1: $\lambda, p$ locii under PT for $\alpha=0.3,0.4,0.5,0.6$.

+0.5 respectively). Given that the predicted values of $\lambda^{E U}$ are over-predicted by about 60 on average, within the relevant range of audit probabilities, this adjustment in stigma is insufficient to align the predictions of EUT with the data, but it still allows reasonably accurate predictions using prospect theory.

\subsection{Some additional issues with the rate of stigma}

There are three additional issues with respect to stigma costs.

1. The Yitzhaki result applies in the absence of stigma. Proposition 1 indicates that, under EUT and in the presence of stigma, the effect of the tax rate on the amount evaded is ambiguous. We look at the Yitzhaki result here as an empirical question. Using (5.8) we plot, in Figure 6.2, the derivative of declared income $D$ with respect to the tax rate for the case of EUT. We use the values $\lambda=2, p=0.3, \beta=0.5, t=0.3$ for calibration purposes ${ }^{27}$. Figure 6.2 plots $\partial D / \partial t$ for a wide range of values of the

\footnotetext{
${ }^{27}$ These set of values are identical to the ones we use to calibrate the prospect theory model with the exception of the preference parameter $\beta$. In prospect theory, $\beta \approx 0.88$ and loss aversion performs a role similar (but not identical) to risk aversion. However, restricting $\beta \approx 0.88$ under EUT would imply close to risk neutrality. Hence, we use the more realistic value of $\beta=0.5$.
} 
stigma rate, namely, $s \in[0,2]$. It is clear that for realistic parameter values, the Yitzhaki puzzle survives the introduction of stigma under EUT because $\partial D / \partial t>0$ (although $\partial^{2} D / \partial t^{2}<0$ ).

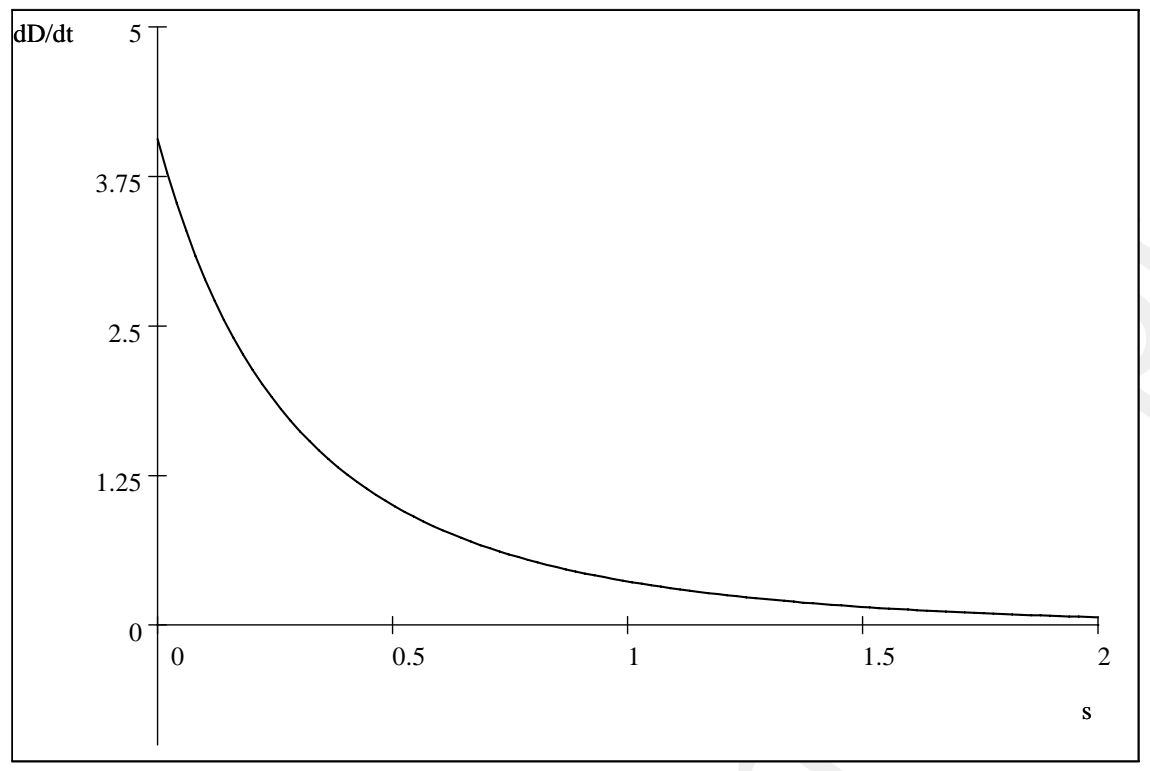

Figure 6.2: The derivative of declared income with respect to the tax rate

2. In the main paper, we follow the original treatment of stigma in Gordon and specify the loss due to stigma as $s(W-D)$. Does this play a role in allowing us to overturn the Yitzhaki result under prospect theory? To examine this let us specify a more general form of the loss due to stigma. It is often argued that stigma costs are lower when the tax rate is high or the tax system is perceived as being unfair; for example, see Gordon (1989) and Brooks (2001). This suggests that in practice, stigma costs are given by

$$
\psi(t)(W-D)
$$

where $\psi(t)$ is a function that depends on the tax rate and satisfies the restriction

$$
\psi^{\prime}(t) \leq 0
$$

With costs of stigma formulated as in (6.1) and (6.2), it is easy to check that the equilibrium condition under prospect theory, the analogue of (5.11), becomes

$$
\begin{array}{cccc}
\text { Case : I } & D=0 & \text { if } & \left(\frac{1}{\theta}\right) \frac{w^{+}(1-p)}{w^{-}(p)}>\left(\lambda+\frac{\psi(t)}{t}\right)^{\beta} \\
\text { Case : II } & D \in[0, W] & \text { if } & \left(\frac{1}{\theta}\right) \frac{w^{+}(1-p)}{w^{-}(p)}=\left(\lambda+\frac{\psi(t)}{t}\right)^{\beta} \\
\text { Case : III } & D=W & \text { if } & \left(\frac{1}{\theta}\right) \frac{w^{+}(1-p)}{w^{-}(p)}<\left(\lambda+\frac{\psi(t)}{t}\right)^{\beta} .
\end{array}
$$


From (6.3), an increase in the tax rate is more conducive for case III as compared to case I (a necessary condition for the Yitzhaki puzzle to be overturned) if

$$
\frac{d}{d t}\left(\frac{\psi(t)}{t}\right) \leq 0
$$

It is immediately clear that a sufficient condition for (6.4) to hold is given in (6.2), which was a-priori the preferred restriction. In the main body of the paper we use $\psi(t)=s$, where $s$ is a constant; this satisfies (6.2). Hence, more general formulations of stigma using prospect theory also refute the Yitzhaki result.

3. Stigma needs to be separated from guilt ${ }^{28}$. One might feel guilty about evading taxes even if "not caught" by the tax authorities. We illustrate the issues in the context of a fixed probability of detection. Suppose that in addition to the usual penalties levied by the government the taxpayer also suffers from guilt $g(W-D)$, where $g>0$ is the guilt costs arising from a dollar of tax evaded. Proceeding in the usual way we can check that the value function under prospect theory is now given by

$$
V(D ; t, s, \lambda, \theta, g, W)=(W-D)^{\beta} h(t, s, \lambda, \theta, g)
$$

where

$$
h(t, s, \lambda, \theta, g)=(t-g)^{\beta}\left[w^{+}(1-p)-\theta\left(\frac{\lambda t+g+s}{t-g}\right)^{\beta} w^{-}(p)\right] .
$$

The decision criteria of the taxpayer is given by (5.11) except that the value of $h($. is replaced by that given in (6.6). Restricting to real valued functions (so $t>g$ ), an increase in the tax rate increases $h(t, s, \lambda, \theta, g)$. Using (5.11), this is a necessary condition to move from $D=W$ (Case-III) to $D=0$ (Case-I), which runs counter to Yitzhaki's result as claimed earlier. Proceeding analogously it is easy to check that an increase in guilt cost per dollar, $g$, lowers $h(t, s, \lambda, \theta, g)$, which is a necessary condition to move from $D=0$ (Case-I) to $D=W$ (Case-III) (i.e. an increase in guilt lowers evasion). The comparative static results with respect to other parameters such as $\theta$ can also be checked to hold. Hence, the presence of guilt does not alter our results. It is straightforward to check that the qualitative comparative static effects of stigma costs are unaltered.

\section{Conclusions}

Why should people pay taxes when, given relatively low audit probabilities and penalties, evasion should be extremely attractive, at least to expected utility maximizers? This is

\footnotetext{
${ }^{28} \mathrm{We}$ are grateful to a referee for pointing this out.
} 
puzzling, given "too much observed compliance" relative to the predictions of expected utility theory. This paper considers an alternative theoretical model that is based on cumulative prospect theory. Prospect theory characterizes individuals as loss averse with respect to some reference income. Furthermore, these individuals overweight small probabilities while underweighting large ones.

Our results show that despite the existence of low audit probabilities and penalty rates in actual practice, the magnitude of tax evasion predicted by prospect theory is consistent with the data. Individuals are also predicted to respond to an increase in the tax rate by increasing the amount evaded. This accords with the bulk of the evidence, but contrasts with the converse prediction made by expected utility theory. These considerations would, to our mind, suggest that an increased use be made of prospect theory in formulating tax evasion problems. ${ }^{29}$

In applying prospect theory, we do not fix the parameter values of the model to make it fit the evidence on tax evasion. Instead, we use the parameters of human choice that are revealed from independent experimental evidence. When such parameters are not available we conduct a robustness analysis. Prospect theory is able to explain the tax evasion puzzles. Hence, the paper concludes that the behavior of tax payers provides strong support for prospect theory.

\section{A ppendix}

Proof of Proposition 1From (2.1), (2.2) and (3.1) we get

$$
\begin{gathered}
\frac{\partial U}{\partial D}=(s+\lambda t) p u^{\prime}\left(Y_{C}\right)-t(1-p) u^{\prime}\left(Y_{N C}\right)-p^{\prime}\left[u\left(Y_{N C}\right)-u\left(Y_{C}\right)\right] \\
\frac{\partial^{2} U}{\partial D^{2}}=p^{\prime \prime}\left[u\left(Y_{C}\right)-u\left(Y_{N C}\right)\right]+2(s+\lambda t) p^{\prime} u^{\prime}\left(Y_{C}\right)+2 t p^{\prime} u^{\prime}\left(Y_{N C}\right) \\
+(s+\lambda t)^{2} p u^{\prime \prime}\left(Y_{C}\right)+t^{2}(1-p) u^{\prime \prime}\left(Y_{N C}\right) \\
\frac{\partial^{2} U}{\partial D \partial s}=p u^{\prime}\left(Y_{C}\right)-(s+\lambda t)(W-D) p u^{\prime \prime}\left(Y_{C}\right)-(W-D) p^{\prime} u^{\prime}\left(Y_{C}\right)>0 \\
\frac{\partial^{2} U}{\partial D \partial \lambda}=t p u^{\prime}\left(Y_{C}\right)-t(s+\lambda t) p u^{\prime \prime}\left(Y_{C}\right)(W-D)-t(W-D) p^{\prime} u^{\prime}\left(Y_{C}\right)>0
\end{gathered}
$$

\footnotetext{
${ }^{29}$ Kanbur et al. (2004) set out the restrictions necessary for the first order approach of principal-agent theory to hold in a prospect theory analysis of optimal taxation with moral hazard but without tax evasion. Their usage of prospect theory relies mainly on reference dependence and loss aversion. Dhami and al-Nowaihi incorporate all three components (i.e. reference dependence, loss aversion and non-linear weighting of probabilities), in an optimal tax analysis in the presence of tax evasion. The latter's simulation shows that the revenue maximizing tax rate is approximately 33 percent, which is not unrepresentative of Western democracies.
} 


$$
\begin{aligned}
\frac{\partial^{2} U}{\partial D \partial t}= & \left\{\lambda p+[W+\lambda(W-D)]\left[(s+\lambda t) p A\left(Y_{C}\right)-p^{\prime}\right]\right\} u^{\prime}\left(Y_{C}\right) \\
& -\left\{(1-p)\left[1+t D A\left(Y_{N C}\right)\right]-D p^{\prime}\right\} u^{\prime}\left(Y_{N C}\right)
\end{aligned}
$$

where $A(Y)=-u^{\prime \prime}(Y) / u^{\prime}(Y)$ is the coefficient of absolute risk aversion. All terms in (8.2) are negative except, possibly, the first. If $p^{\prime \prime}(D) \geq 0$, then the first term will be non-positive. Hence $p^{\prime \prime}(D) \geq 0$ is sufficient, but not necessary, for $\frac{\partial^{2} U}{\partial D^{2}}$ to be negative.

Let $D^{*}(t, s, \lambda, W)$ maximize the taxpayer's expected utility (3.1) given the values of the parameters $t, s, \lambda, W$.

(a) Consider an interior maximum (i.e., $0<D^{*}<W$ ). Hence, at $D=D^{*}, \frac{\partial U}{\partial D}=0$ and $\frac{\partial^{2} U}{\partial D^{2}} \leq 0$. If $\frac{\partial^{2} U}{\partial D^{2}}=0$, then $D^{*}$ is a critical point of $\frac{\partial U}{\partial D}$. If $\frac{\partial^{2} U}{\partial D^{2}} \neq 0$, then $D^{*}$ is a regular point of $\frac{\partial U}{\partial D}$. Assume $D^{*}$ is a regular point; then $\frac{\partial^{2} U}{\partial D^{2}}<0$ at $D=D^{*}$. Hence, from the implicit function theorem, $D^{*}(t, s, \lambda, W)$ is unique, continuously differentiable with

$$
\frac{\partial D^{*}}{\partial s}=-\frac{\partial^{2} U}{\partial D \partial s} / \frac{\partial^{2} U}{\partial D^{2}} ; \frac{\partial D^{*}}{\partial \lambda}=-\frac{\partial^{2} U}{\partial D \partial \lambda} / \frac{\partial^{2} U}{\partial D^{2}} ; \frac{\partial D^{*}}{\partial t}=-\frac{\partial^{2} U}{\partial D \partial t} / \frac{\partial^{2} U}{\partial D^{2}},
$$

at least locally. It follows that the signs of $\frac{\partial D^{*}}{\partial s}, \frac{\partial D^{*}}{\partial \lambda}$ and $\frac{\partial D^{*}}{\partial t}$ are those of $\frac{\partial^{2} U}{\partial D \partial s}, \frac{\partial^{2} U}{\partial D \partial \lambda}$ and $\frac{\partial^{2} U}{\partial D \partial t}$, respectively. It then follows from (8.3) and (8.4) that $\frac{\partial D^{*}}{\partial s}>0$ and $\frac{\partial D^{*}}{\partial \lambda}>0$.

(b) Assume the maximum lies on the boundary. If $D^{*}$ is on the lower boundary (i.e., $D^{*}=0$ ), then, clearly, $D^{*}$ is non-decreasing. Suppose $D^{*}$ is on the upper boundary (i.e., $\left.D^{*}=W\right)$. Then, at $D=D^{*}, \frac{\partial U}{\partial D} \geq 0$, but from (8.3) and (8.4), we see that $\frac{\partial U}{\partial D}$ is a strictly increasing function of each of $s$ and $\lambda$. Hence an increase in either $s$ or $\lambda$ will make $\frac{\partial U}{\partial D}$ strictly positive. Thus a reduction in $D$ would reduce welfare. Hence, $D^{*}$ cannot decrease as a result of an increase in either $s$ or $\lambda$.

(c) The first term of (8.5) is positive but the second is negative. Hence, $\frac{\partial D^{*}}{\partial t}$ is ambiguous. QED.

P roof of P roposition 2Set $p^{\prime \prime}(D)=p^{\prime}(D)=0$ and $s=0$ in (8.1), (8.2) and (8.5) to get

$$
\begin{gathered}
\frac{\partial U}{\partial D}=\lambda t p u^{\prime}\left(Y_{C}\right)-t(1-p) u^{\prime}\left(Y_{N C}\right) \\
\frac{\partial^{2} U}{\partial D^{2}}=\lambda^{2} t^{2} p u^{\prime \prime}\left(Y_{C}\right)+t^{2}(1-p) u^{\prime \prime}\left(Y_{N C}\right)<0 \\
\frac{\partial^{2} U}{\partial D \partial t}=\lambda p\left\{1+t[W+\lambda(W-D)] A\left(Y_{C}\right)\right\} u^{\prime}\left(Y_{C}\right) \\
-(1-p)\left[1+t D A\left(Y_{N C}\right)\right] u^{\prime}\left(Y_{N C}\right) .
\end{gathered}
$$

(a) Consider an interior maximum (i.e., $0<D^{*}<W$ ). Hence, at $D=D^{*}, \frac{\partial U}{\partial D}=0$. Set $\frac{\partial U}{\partial D}=0$ in $(8.6)$ to get

$$
1-p=\frac{\lambda p u^{\prime}\left(Y_{C}\right)}{u^{\prime}\left(Y_{N C}\right)}
$$


Substitute from (8.9) into (8.8) to get

$$
\frac{\partial^{2} U}{\partial D \partial t}=\lambda t p u^{\prime}\left(Y_{C}\right)\left\{(1+\lambda)(W-D) A\left(Y_{C}\right)+D\left[A\left(Y_{C}\right)-A\left(Y_{N C}\right)\right]\right\}
$$

Assuming non-increasing absolute risk aversion gives $A\left(Y_{C}\right) \geq A\left(Y_{N C}\right)$. It follows from (8.10) that $\frac{\partial^{2} U}{\partial D \partial t}>0$. Hence, and in the light of (8.7), $\frac{\partial D^{*}}{\partial t}>0$.

(b) Assume the maximum lies on the boundary. If $D^{*}$ is on the lower boundary (i.e., $D^{*}=0$ ), then, clearly, $D^{*}$ is non-decreasing. Suppose $D^{*}$ is on the upper boundary (i.e., $\left.D^{*}=W\right)$, then, at $D=D^{*}=W, \frac{\partial U}{\partial D} \geq 0$. Hence, from (8.6)

$$
1-p \leq \frac{\lambda p u^{\prime}\left(Y_{C}\right)}{u^{\prime}\left(Y_{N C}\right)}
$$

From (8.8) and (8.11) we get

$$
\frac{\partial^{2} U}{\partial D \partial t} \geq \lambda t p W u^{\prime}\left(Y_{C}\right)\left[A\left(Y_{C}\right)-A\left(Y_{N C}\right)\right]>0 .
$$

From (8.12), we see that $\frac{\partial U}{\partial D}$ is a strictly increasing function of $t$. Hence an increase in $t$ will make $\frac{\partial U}{\partial D}$ strictly positive. Thus a reduction in $D$ would reduce welfare. Hence, $D^{*}$ cannot decrease as a result of an increase in $t$. QED.

P roof of Proposition 3From (2.1), (2.2) and (4.1) we get

$$
\begin{gathered}
X_{N C}=W-t D-R, 0 \leq D \leq W \\
X_{C}=(1-t) W-(s+\lambda t)(W-D)-R, 0 \leq D \leq W .
\end{gathered}
$$

For the taxpayer always to be in the domain of gains if not caught, we must have

$$
X_{N C} \geq 0 \text { for all } D \in[0, W] \text {. }
$$

Similarly, for the taxpayer always to be in the domain of losses if caught, we must have

$$
X_{C} \leq 0 \text { for all } D \in[0, W]
$$

In particular, for $D=W,(8.13)$ and $(8.15)$ give $^{30}$

$$
R \leq(1-t) W
$$

\footnotetext{
${ }^{30}$ Note that (8.13)-(8.16), must hold for any $D \in[0, W]$; hence, we get that the reference point must satisfy

$$
R \in[W-t D-[s+t(1+\lambda)](W-D), W-t D] \equiv[A, B]
$$

where $A$ and $B$ are respectively the lower and upper limits of the interval. Notice that $\frac{d A}{d D}=s+t \lambda>0$ and $\frac{d B}{d D}=-t<0$. Hence, as one moves from $D=0$ to $D=W$ one gets nested intervals within which $R$ must lie. Since $D \in[0, W]$ we need only check the case $D=W$ to ensure that the reference point holds for all possible values of $D$.
} 
Similarly, for $D=W,(8.14)$ and (8.16) give

$$
R \geq(1-t) W
$$

From (8.17) and (8.18) we get $R=(1-t) W$ as the unique reference point. QED.

P roof of Proposition 4From (4.7) we get

$$
\begin{aligned}
& \frac{\partial V}{\partial D}=(W-D)^{\beta-1}\left\{\begin{array}{c}
\theta(s+\lambda t)^{\beta}\left[\beta w^{-}-(W-D)\left(w^{-}\right)^{\prime} p^{\prime}\right] \\
-t^{\beta}\left[\beta w^{+}+(W-D)\left(w^{+}\right)^{\prime} p^{\prime}\right]
\end{array}\right\} \\
& \frac{\partial^{2} V}{\partial D^{2}}=2 \beta(W-D)^{\beta-1}\left[t^{\beta}\left(w^{+}\right)^{\prime}+\theta(s+\lambda t)^{\beta}\left(w^{-}\right)^{\prime}\right] p^{\prime} \\
& +\beta(1-\beta)(W-D)^{\beta-2}\left[\theta(s+\lambda t)^{\beta} w^{-}-t^{\beta} w^{+}\right] \\
& +(W-D)^{\beta}\left[t^{\beta}\left(w^{+}\right)^{\prime \prime}-\theta(s+\lambda t)^{\beta}\left(w^{-}\right)^{\prime \prime}\right]\left(p^{\prime}\right)^{2} \\
& -(W-D)^{\beta}\left[t^{\beta}\left(w^{+}\right)^{\prime}+\theta(s+\lambda t)^{\beta}\left(w^{-}\right)^{\prime}\right] p^{\prime \prime} \\
& \frac{\partial^{2} V}{\partial D \partial \theta}=\beta(s+\lambda t)^{\beta}(W-D)^{\beta-1} w^{-}-(s+\lambda t)^{\beta}(W-D)^{\beta}\left(w^{-}\right)^{\prime} p^{\prime}>0 \\
& \frac{\partial^{2} V}{\partial D \partial s}=\beta^{2} \theta(s+\lambda t)^{\beta-1}(W-D)^{\beta-1} w^{-}-\beta \theta(s+\lambda t)^{\beta-1}(W-D)^{\beta}\left(w^{-}\right)^{\prime} p^{\prime}>0 \\
& \frac{\partial^{2} V}{\partial D \partial \lambda}=\beta^{2} \theta t(s+\lambda t)^{\beta-1}(W-D)^{\beta-1} w^{-}-\beta \theta t(s+\lambda t)^{\beta-1}(W-D)^{\beta}\left(w^{-}\right)^{\prime} p^{\prime}>0 \\
& \frac{\partial^{2} V}{\partial D \partial t}=\beta(W-D)^{\beta-1}\left\{\begin{array}{c}
\lambda \theta(s+\lambda t)^{\beta-1}\left[\beta w^{-}-(W-D)\left(w^{-}\right)^{\prime} p^{\prime}\right] \\
-t^{\beta-1}\left[\beta w^{+}+(W-D)\left(w^{+}\right)^{\prime} p^{\prime}\right]
\end{array}\right\}
\end{aligned}
$$

where $w^{-}$is evaluated at $p(D)$ and $w^{+}$is evaluated at $1-p(D)$.

Note that the first term in (8.20) is negative. However, the other three terms are ambiguous. Hence, the sign of $\frac{\partial^{2} V}{\partial D^{2}}$ is ambiguous.

Let $D^{*}(t, s, \lambda, \theta, W)$ maximize (4.7) given the values of the parameters $t, s, \lambda, \theta, W$.

(a) Consider an interior maximum (i.e., $0<D^{*}<W$ ). Hence, at $D=D^{*}, \frac{\partial U}{\partial D}=0$. Set $\frac{\partial U}{\partial D}=0$ in $(8.19)$ to get

$$
t^{\beta-1}\left[\beta w^{+}+(W-D)\left(w^{+}\right)^{\prime} p^{\prime}\right]=t^{-1} \theta(s+\lambda t)^{\beta}\left[\beta w^{-}-(W-D)\left(w^{-}\right)^{\prime} p^{\prime}\right] .
$$

From (8.24) and (8.25) we get

$$
\frac{\partial^{2} V}{\partial D \partial t}=-\frac{\beta \theta s(s+\lambda t)^{\beta-1}}{t(W-D)^{1-\beta}}\left[\beta w^{-}-(W-D)\left(w^{-}\right)^{\prime} p^{\prime}\right]<0 .
$$

Since $\beta>0, w^{-}>0, W \geq D, p^{\prime} \leq 0,\left(w^{-}\right)^{\prime}>0$, it follows that $\beta w^{-}-(W-D)\left(w^{-}\right)^{\prime} p^{\prime}>$ 0 . Hence, from (8.26), it is clear that $\frac{\partial^{2} V}{\partial D \partial t}(D ; t, s, \lambda, \theta, W)<0$. 
If $\frac{\partial^{2} V}{\partial D^{2}}=0$, then $D^{*}$ is a critical point of $\frac{\partial V}{\partial D}$. If $\frac{\partial^{2} V}{\partial D^{2}} \neq 0$, then $D^{*}$ is a regular point of $\frac{\partial V}{\partial D}$. Assume $D^{*}$ is a regular point; then $\frac{\partial^{2} V}{\partial D^{2}}<0$ at $D=D^{*}$. Hence, from the implicit function theorem, $D^{*}(t, s, \lambda, \theta, W)$ is unique, continuously differentiable with

$$
\frac{\partial D^{*}}{\partial \theta}=-\frac{\partial^{2} V}{\partial D \partial \theta} / \frac{\partial^{2} V}{\partial D^{2}} ; \frac{\partial D^{*}}{\partial s}=-\frac{\partial^{2} V}{\partial D \partial s} / \frac{\partial^{2} V}{\partial D^{2}} ; \frac{\partial D^{*}}{\partial \lambda}=-\frac{\partial^{2} V}{\partial D \partial \lambda} / \frac{\partial^{2} V}{\partial D^{2}} ; \frac{\partial D^{*}}{\partial t}=-\frac{\partial^{2} V}{\partial D \partial t} / \frac{\partial^{2} V}{\partial D^{2}},
$$

at least locally. It follows that the signs of $\frac{\partial D^{*}}{\partial \theta}, \frac{\partial D^{*}}{\partial s}, \frac{\partial D^{*}}{\partial \lambda}$ and $\frac{\partial D^{*}}{\partial t}$ are those of $\frac{\partial^{2} V}{\partial D \partial \theta}, \frac{\partial^{2} V}{\partial D \partial s}$, $\frac{\partial^{2} V}{\partial D \partial \lambda}$ and $\frac{\partial^{2} V}{\partial D \partial t}$, respectively. It then follows from (8.21), (8.22), (8.23) and (8.26) that $\frac{\partial D^{*}}{\partial \theta}>0, \frac{\partial D^{*}}{\partial s}>0, \frac{\partial D^{*}}{\partial \lambda}>0$ and $\frac{\partial D^{*}}{\partial t}<0$.

(b) Assume the maximum lies on the boundary. If $D^{*}$ is on the upper boundary (i.e., $D^{*}=W$ ), then, clearly, $D^{*}$ is non-increasing function of $t$. Suppose $D^{*}$ is on the lower boundary (i.e., $D^{*}=0$ ). Then, at $D=D^{*}=0, \frac{\partial V}{\partial D} \leq 0$. Hence, from (8.19), we get

$$
t^{\beta-1}\left[\beta w^{+}+W\left(w^{+}\right)^{\prime} p^{\prime}\right] \geq t^{-1} \theta(s+\lambda t)^{\beta}\left[\beta w^{-}-W\left(w^{-}\right)^{\prime} p^{\prime}\right] .
$$

From (8.24) and (8.27) we get

$$
\frac{\partial^{2} V}{\partial D \partial t} \leq-\frac{\beta \theta s(s+\lambda t)^{\beta-1}}{t W^{1-\beta}}\left[\beta w^{-}-W\left(w^{-}\right)^{\prime} p^{\prime}\right]<0,
$$

but from (8.28), we see that $\frac{\partial V}{\partial D}$ is a strictly decreasing function of $t$. Hence an increase in $t$ will make $\frac{\partial V}{\partial D}$ strictly negative. Thus an increase in $D$ would reduce welfare. Hence, $D^{*}$ cannot increase as a result of an increase in $t$.

A similar argument shows that $D^{*}$ is non-decreasing function of each of $s, \lambda$ and $\theta$. QED.

\section{R eferences}

al-Nowaihi, A., Dhami, S., 2006. A simple derivation of Prelec's probability weighting function. Journal of Mathematical Psychology 50 (6), 521-524.

al-Nowaihi, A., Pyle, D., 2000. Income tax evasion: a theoretical analysis. In: MacDonald, A., Pyle, D. (Eds.). Illicit activity: The economics of crime and tax fraud. Aldershot: Ashgate, 249-266.

Allingham, M.G., Sandmo, A., 1972. Income tax evasion: a theoretical analysis. Journal of Public Economics 1, 323-238.

Alm, J., McClelland, G.H., Schulze, W. D., 1992. Why do people pay taxes? Journal of Public Economics 48, 21-38.

Andreoni, J., Erard, B, and Feinstein, J., 1998. Tax Compliance. Journal of Economic Literature 36, 818-860.

Baldry, J.C., 1987. Income tax evasion and the tax schedule: some experimental results. Public Finance 42, 355-384. 
Bastable, C., 1892. Public Finance. London: Macmillan and Co., Limited.

Benartzi, S., Thaler, R. H., 1995. Myopic loss aversion and the equity premium puzzle. Quarterly Journal of Economics 110, 73-92.

Benjamini, Y., Maital, S., 1985. Optimal tax evasion policy: behavioral aspects. In: Gaertner, W., Wenig, A., (Eds.). The Economics of the Shadow Economy. Berlin: Springer-Verlag, 140-158.

Bernasconi, M., 1998. Tax evasion and orders of risk aversion. Journal of Public Economics $67,123-134$.

Bernasconi, M., Zanardi, A., 2004. Tax evasion, tax rates and reference dependence. FinanzArchiv 60, 422-445.

Besley, T., Coate, S., 1992. Understanding welfare stigma: taxpayer resentment and statistical discrimination. Journal of Public Economic 48, 165-183.

Brooks, N., 2001. Key issues in income tax: challenges of tax administration and compliance. Paper presented at the 2001 Tax conference of the Asian Development Bank.

Camerer, C., 2000. Prospect theory in the wild: evidence from the field. In: Kahneman, D., Tversky, A. (Eds.). Choices, values and frames. Cambridge: Cambridge University Press, 288-300.

Camerer, C.F., Ho, T. H., 1994. Violations of the betweenness axiom and nonlinearity in probability. Journal of Risk and Uncertainty 8, 167-196.

Camerer, C.F., Loewenstein, G., Rabin, M., 2004. Advances in Behavioral Economics. Princeton: Princeton University Press.

Clotfelter, C.T., 1983. Tax evasion and tax rates: an analysis of individual returns. Review of Economics and Statistics 65, 363-373.

Dhami, S., al-Nowaihi, A., 2005. Why do people pay taxes? Prospect theory versus expected utility theory. University of Leicester Discussion Papers in Economics 05/23.

Eide, E., 2001. Rank dependent expected utility models of tax evasion. mimeo., University of Oslo.

Elffers, H., Hessing, D. J., 1997. Influencing the prospects of tax evasion. Journal of Economic Psychology 18, 289-304.

Feinstein, J. S., 1991. An econometric analysis of income tax evasion and its detection. RAND Journal of Economics 22, 14-35.

Friedland, N., Maital, S., Rutenberg, A., 1978. A simulation study of income tax evasion. Journal of Public Economics 10, 107-116.

Gordon, J. P. F., 1989. Individual morality and reputation costs as deterrents to tax evasion. European Economic Review 33, 797-805.

Kahneman, D., Tversky, A., 1979. Prospect theory: an analysis of decision under risk. Econometrica 47, 263-291. 
Kahneman, D., Tversky, A. (Eds.). 2000. Choices, values and frames. Cambridge: Cambridge University Press.

Kanbur, R., Pirtilla, J., Tuomala, M., 2004. Moral hazard, income taxation and prospect theory. mimeo.

Luce, R. D., 2001. Reduction invariance and Prelec's weighting functions. Journal of Mathematical Psychology 45, 167-179.

Mankiw, N. G, Zeldes, S., 1991. The consumption of stockholders and non-stockholders. Journal of Financial Economics 29, 97-112.

Needham, W.R., 2002. The political economy background to the capitalist development of Canada. mimeo. University of Waterloo.

Omer, T. C., Yetman, R.J., 2002. Near zero taxable income reporting by Nonprofit Organizations. Paper presented at the American Accounting Association Meetings.

Prelec, D., 1998. The probability weighting function. Econometrica 60, 497-528.

Pudney, S.E., Pyle, D., Saruc, T., 2000. Income tax evasion: an experimental approach. In: MacDonald, A., Pyle, D. (Eds.). Illicit activity: the economics of crime and tax fraud. Aldershot: Ashgate, 267-289.

Pudney, S.E., Hernandez, M., Hancock, R., 2002. The welfare cost of means-testing: pensioner participation in income support. Discussion Papers in Economics 03/2, Department of Economics, University of Leicester.

Quiggin, J., 1993. Generalized expected utility theory: the rank-dependent expected utility model. Amsterdam: Kluwer-Nijhoff.

Segal, U., Spivak, A., 1990. First order versus second order risk aversion. Journal of Economic Theory 51, 111-125.

Skinner, J., Slemrod, J., 1985. An economic perspective on tax evasion. National Tax Journal 38, 345-353.

Slemrod, J., Yitzhaki, S., 2002. Tax avoidance, evasion and administration. In: Auerbach, A.J., Feldstein, M. (Eds.). Handbook of Public Economics, Vol. 3. Amsterdam: Elsevier Science, chapter 22, 1423-1470.

Starmer, C., 2000. Developments in non-expected utility theory: the hunt for a descriptive theory of choice under risk. Journal of Economic Literature 38, 332-382.

Tversky, A., Kahneman, D., 1992. Advances in prospect theory: cumulative representation of uncertainty. Journal of Risk and Uncertainty 5, 297-323.

Yaniv, G., 1999. Tax compliance and advance tax payments: a prospect theory analysis. National Tax Journal 52, 753-764.

Yitzhaki, S., 1974. A note on income tax evasion: a theoretical analysis. Journal of Public Economics 3, 201-202. 